\title{
ALEXANDRIA
}

Revista de Educação em Ciência e Tecnologia

ALEXANDRIA

\section{Abordagem Temática no Ensino de Ciências: Caracterização de Propostas Destinadas ao Ensino Médio}

\section{Thematic Approach in Science Teaching: Characterization of Proposals for in High School}

\section{Karine Raquiel Halmenschlager ${ }^{\mathrm{a}}$; Demétrio Delizoicov ${ }^{\mathrm{a}}$}

a Departamento de Metodologia de Ensino, Universidade Federal de Santa Catarina, Florianópolis, Brasil karine.h@ufsc.br, demetrio.neto@ufsc.br

Palavras-chave:

Ensino de ciências. Abordagem temática. Ensino médio.

\begin{abstract}
Resumo: Este trabalho visa mapear iniciativas pioneiras relativas à inserção de propostas de abordagem de temas no ensino de Física, de Química e de Biologia, no ensino médio. Realizou-se uma busca em eventos e periódicos nacionais, considerando-se o recorte temporal de 2006 a 2011, definido a partir de marcos históricos relacionados à edição dos parâmetros e orientações curriculares nacionais. Para análise, os estudos localizados foram agrupados de acordo com o tipo de inserção que se denominou de ampliada ou pontual. Em seguida, as propostas temáticas foram caracterizadas a partir dos parâmetros natureza do tema e função dos conceitos científicos. Dentre os resultados predominam inserções pontuais, pautadas em temas de natureza conceitual e contextual, em que a temática em estudo é, em geral, subdeterminada pela conceituação científica. Contudo, a análise sinaliza que parece estar emergindo uma compreensão mais ampla de conteúdo escolar, a qual não se limita à estrutura conceitual das disciplinas.
\end{abstract}

\section{Keywords:}

Science teaching.

Thematic approach.

High school.

\begin{abstract}
This work aims to map pioneering initiatives related to the insertion of proposals to thematic approach in Physics, Chemistry and Biology Teaching, in high school. A literature review was carried out in event proceedings and Brazilian journals, considering the period from 2006 to 2011, defined from historical milestones related to the edition of National Curricular Parameters. For analysis, the localized studies were grouped according to the type of insertion that was denominated as expanded or punctual. Then, the proposals were depicted under two parameters: nature of the theme and purpose of scientific concepts. Among the results, it is predominant the punctual implementation, grounded on conceptual and contextual themes, in which the topic studied is generally determined by the scientific conceptualization. However, the analysis of these publications indicates that a broader understanding of school content seems to be emerging, which is not limited to the conceptual framework of the school disciplines.
\end{abstract}




\section{Introdução}

Nas últimas décadas, são significativas as discussões em torno de questões curriculares e metodológicas relativas ao ensino médio (EM). Documentos e programas propostos pelo Ministério da Educação (MEC) (BRASIL, 2013; 2006) apresentam estratégias que visam melhorar índices de evasão, repetência e distorção série-idade, principais demandas do EM, objetivando a inclusão e manutenção do aluno na escola. Em relação às questões curriculares, alguns documentos trazem a necessidade de inserção de novos elementos ao currículo, como se propõe com os Parâmetros Curriculares Nacionais para o Ensino Médio (PCNEM) (BRASIL, 2000), com as Orientações Educacionais Complementares aos Parâmetros Curriculares Nacionais (PCN+) (BRASIL, 2002) e com as Orientações Curriculares para o Ensino Médio (OCEM) (BRASIL,2006) ${ }^{1}$.

Esses documentos defendem um ensino que promova a formação integral do aluno, preparando-o para se adaptar ao mundo do trabalho, como cidadão consciente e transformador de sua realidade. Eles introduzem elementos que exigem uma compreensão de currículo escolar não contemplada em práticas curriculares anteriores e constituem, portanto, desafios para sua implementação. Para o desenvolvimento dessa perspectiva formativa, sugere-se a organização do programa escolar por meio dos eixos integradores contextualização, problematização e interdisciplinaridade (BRASIL, 2000). Já a estrutura curricular sugerida tem por base Temas Estruturadores e Unidades Temáticas (BRASIL, 2002). Essas orientações são complementadas, ainda, com a citação de perspectivas de abordagem de temas encontradas na literatura, a exemplo de Temas Sociais, Temas Geradores, Situação de Estudo (SE), Ilha Interdisciplinar de Racionalidade (IIR) e temáticas envolvendo a tríade Ciência, Tecnologia, Sociedade (CTS) (BRASIL, 2006). O desafio que se apresenta, portanto, é a articulação da conceituação científica com temas para a proposição dos conteúdos de ensino, diferentemente de uma tradição histórica que considera conteúdos apenas uma seleção de conceitos científicos a serem distribuídos para estudo durante os anos de escolarização.

A inserção desses novos elementos ao currículo escolar impõe aos educadores pensar estratégias tanto para a abordagem quanto para a seleção dos conhecimentos historicamente produzidos e sistematizados que serão trabalhados em sala de aula. Desta forma, além da necessidade de novas metodologias para a abordagem do que constitui o que é chamado, tradicionalmente, de conhecimento escolar — os conteúdos científicos —, faz-se pertinente considerar a inserção de questões relacionadas ao contexto sociocultural dos alunos, ao

\footnotetext{
${ }^{1}$ Além desses documentos, atualmente, está em discussão a Base Nacional Comum Curricular (BNCC) que tem por objetivo orientar a organização dos programas escolares nas escolas brasileiras. $\mathrm{O}$ referido documento propõe que a organização do currículo se dê a partir de Unidades de Conhecimento (UC). No que diz respeito à Ciências da Natureza, as UC abarcam, especialmente, elementos conceituais estruturantes das disciplinas.
} 
"mundo do trabalho" e ao "mundo da vida" como conteúdo escolar. Ou seja, o conhecimento tratado na escola não se limita ao conteúdo científico, pois os problemas e as questões contextuais, representados a partir de uma temática, também podem configurar conteúdo a ser ensinado e aprendido.

Considerar esses aspectos no processo educacional implica na seleção de questões a serem trabalhadas em sala de aula que, efetivamente, mobilizem o aluno a aprender. Diversos autores, a exemplo de Strieder et al. (2012), Delizoicov (1991) e Halmenschlager (2014), contudo, chamam a atenção para a necessidade de se estruturar a prática educativa a partir de situações contextuais significativas, que configurem problemas que, de alguma forma, coloquem em confronto os saberes prévios do aluno, que possibilitem, por meio da dialogicidade e da problematização (FREIRE, 2005), um maior nível de entendimento de sua realidade concreta e formas de se relacionar com ela criticamente no sentido de sua transformação.

Entretanto, diante da diversidade de situações que podem ser exploradas em sala de aula, e das diversas perspectivas temáticas sugeridas nas OCEM (BRASIL, 2006), compreende-se que o tema pode apresentar natureza conceitual ou natureza contextual (HALMENSCHLAGER, 2014). A natureza conceitual contempla, principalmente, aspectos relacionados, exclusivamente, com a conceituação científica, e eventual uso dela, a título de exemplificação, em situações da vivência do aluno, sendo a temática expressa a partir de determinado conceito ou de articulações entre diferentes conceitos. Ou seja, tem relação direta com a estrutura conceitual que tradicionalmente orienta a organização dos programas escolares. Temas de natureza contextual, por sua vez, podem estar relacionados, dentre outros, com fenômenos naturais ou tecnológicos, situações representativas de determinado contexto geopolítico, situações problemas e contradições (FREIRE, 2005), questões ambientais.

Além da natureza do tema, para uma melhor compreensão da relação estabelecida entre a temática e o seu desenvolvimento, é necessário se caracterizar a função dos conceitos científicos no processo de organização da proposta, uma vez que a relação de dependência entre temas e conceitos pode ser estabelecida com distintas subdeterminações. Ou seja, tanto os conceitos podem estar subordinados ao tema quanto podem orientar a escolha da temática. Considerando isso, parece fundamental se levar em conta como os recortes selecionados do conhecimento historicamente produzido - incluindo os problemas/situações contextuais, os problemas enfrentados no processo de construção de teorias e conceitos, a dinâmica de produção científica e as relações estabelecidas entre conceitos procedentes das distintas áreas do saber - contribuem ou não para o aluno melhor compreender os temas abordados no currículo escolar. $\mathrm{Na}$ abordagem desses temas, o desafio está em se estabelecer relações entre uma determinada opção temática e a conceituação científica que permite uma interpretação do 
tema por parâmetros inéditos para os alunos, tais como conceitos científicos oriundos dos modelos e teorias científicas, além delas próprias e a sua historicidade. Compreende-se, então, que é necessário o estabelecimento de critérios, distintos daqueles baseados única e exclusivamente em mapas conceituais com origem na estrutura conceitual das disciplinas científicas, de modo a se definir as possibilidades do que será apresentado como conteúdo escolar.

Podemos, portanto, considerar os PCNEM de 2000 como um marco que induz a um olhar distinto para os currículos das escolas de EM no Brasil com seus sucessivos desdobramentos de várias ordens, quer os institucionais, com o advento das duas outras publicações, de 2002 e 2006 pelo MEC, quer aqueles originários das tentativas de implementações por professores que atuam nas escolas de EM, por docentes universitários que formam professores ou por equipes técnicas de secretarias de educação. Deste modo, o objetivo deste artigo é apresentar um mapeamento das iniciativas pioneiras que ocorreram na década seguinte da edição dos PCNEM (BRASIL, 2000). O pressuposto, confirmado por um estudo exploratório inicial (HALMENSCHLAGER, 2011), é que no período de dez anos teriam ocorrido tentativas de se implementar as configurações curriculares emanadas pelos PCNEM (BRASIL, 2000), PCN+ (BRASIL, 2002) e OCEM (BRASIL, 2006). Definiu-se, assim, que a busca dessas iniciativas pioneiras ocorreria até as que foram realizadas em 2011. Priorizou-se, neste estudo, um mapeamento mais detalhado daquelas cuja ênfase estiveram diretamente relacionadas com as proposições da abordagem de temas conforme as OCEM (BRASIL, 2006). Com isso, poderíamos detectar possíveis tendências que estariam emergindo para novas configurações curriculares do EM.

Considerando isso, procurou-se entender quais pressupostos teóricos e metodológicos têm balizado a inclusão da abordagem de temas no EM, a natureza dos temas contemplados e a função dos conceitos científicos. Assim, o presente estudo apresenta elementos, obtidos a partir dos textos localizados com a revisão bibliográfica, que contribuem para compreender, ainda que de forma preliminar e sem considerar a análise de práticas educacionais, como o desafio da implementação de propostas em sintonia com a Abordagem Temática está sendo enfrentado no EM.

\section{Procedimentos metodológicos}

A pesquisa teve natureza qualitativa (LÜDKE; ANDRÉ, 1986) e configurou uma revisão bibliográfica, em atas de eventos e em periódicos, e três marcos históricos, anunciados, definiram o mapeamento: (1) Os Parâmetros Curriculares Nacionais Ensino Médio (PCNEM), editados pelo MEC em 2000; (2) As Orientações Educacionais Complementares aos Parâmetros Curriculares Nacionais (PCN+), publicadas em 2002; e (3) 
As Orientações Curriculares para o Ensino Médio (OCEM), editadas em 2006. Assim, considerou-se o recorte temporal de 2001 a 2011. O foco privilegiado do levantamento sobre abordagem de temas no EM deteve-se nas publicações oriundas como decorrência da síntese publicada sobre essa abordagem nas OCEM de 2006 que, de certo modo, já detectara, incursões de educadores em ciências da natureza na formulação de propostas curriculares baseadas em temas a partir dos dois documentos anteriores.

Adotou-se como critério de delimitação periódicos nacionais classificados como A1 e A2 pelo Qualis Capes na área de ensino ${ }^{2}$ e que possuem publicações acerca do ensino de Ciências: Investigações em Ensino de Ciências (IENCI); Ciência \& Educação; Ensaio Pesquisas em Educação em Ciências; Revista Brasileira de Pesquisa em Educação em Ciências (RBPEC).

Em relação aos eventos, a revisão contemplou trabalhos ${ }^{3}$ publicados nas atas do Encontro Nacional de Pesquisa em Ensino de Ciências (ENPEC), do Encontro de Pesquisa em Ensino de Física (EPEF), do Encontro Nacional de Ensino de Química ${ }^{4}$ (ENEQ) e do Encontro Nacional de Ensino de Biologia (ENEBIO). Optou-se por esses eventos e periódicos porque representam os principais meios de divulgação e socialização dos resultados das pesquisas em ensino de Ciências.

Destaca-se que não se pretendeu realizar um estado da arte (FERREIRA, 2002), nem esgotar o levantamento bibliográfico sobre a relação Abordagem Temática e EM, mas obter indicativos de se e como a abordagem de temas está ocorrendo a partir da edição das OCEM (BRASIL, 2006). Ou seja, buscou-se mapear evidências acerca da proposição e eventual implementação de práticas pautadas na abordagem de temas. A pesquisa, cujos resultados da análise, concluídos em 2014, incluiu, também, obtenção de dados através de entrevistas com autores das publicações, que estiverem envolvidos nas diversas iniciativas de proposições para abordagem de temas destinadas ao EM, foi objeto de outro estudo (HALMENSCHLAGER, 2014).

Para a seleção dos estudos, fez-se uma leitura preliminar do título, resumo e palavraschave, na busca por referências a temas (a exemplo das expressões "temática" e "abordagem temática") ou citações de determinado tema (como "agrotóxicos" e "aquecimento global"), ou às propostas citadas nos documentos oficiais como Situação de Estudo, CTS, Unidade de

\footnotetext{
${ }^{2}$ Tendo como referência o ano de 2011. É importante destacar que embora a revisão aqui apresentada não contemple periódicos classificados como B1 e B2, reconhece-se que eles apresentam contribuições significativas, em termos de quantidade e de qualidade, em relação à temática enfocada neste estudo.

${ }^{3}$ Apresentados como comunicação oral e pôster.

${ }^{4}$ Os trabalhos da modalidade pôster no ENEQ são publicados na forma de resumos e, por isso, optou-se por não considerá-los, pois as informações apresentadas pouco contribuíam para uma maior compreensão do processo de elaboração e implementação das propostas investigadas.
} 
Aprendizagem, Aspectos Sociocientíficos, Projetos Temáticos, Unidades Didáticas. Foram selecionados 442 estudos, sendo 43 deles publicados nos periódicos e 399 nas atas de eventos.

Tabela 01: Número de estudos selecionados por periódico.

\begin{tabular}{|c|c|c|c|c|c|c|c|c|c|c|c|c|}
\hline \multirow[b]{3}{*}{ Ano } & \multicolumn{12}{|c|}{ Periódicos } \\
\hline & \multicolumn{3}{|c|}{ IENCI } & \multicolumn{3}{|c|}{ RBPEC } & \multicolumn{3}{|c|}{$C \& E$} & \multicolumn{3}{|c|}{ ENSAIO } \\
\hline & $\mathbf{A P ^ { 5 }}$ & $\mathrm{AT}^{6}$ & $\%$ & $\mathbf{A P}$ & $\overline{A T}$ & $\%$ & $\mathbf{A P}$ & $\mathbf{A T}$ & $\%$ & AP & AT & $\%$ \\
\hline 2006 & 18 & 1 & 5,5 & 12 & 1 & 8,3 & 24 & 1 & 4,2 & 12 & 0 & 0 \\
\hline 2007 & 18 & 1 & 5,5 & 12 & 2 & 16,6 & 28 & 2 & 7,1 & 18 & 1 & 5,5 \\
\hline 2008 & 18 & 2 & 11,1 & 18 & 2 & 11,1 & 39 & 6 & 15,3 & 18 & 2 & 11,1 \\
\hline 2009 & 24 & 3 & 12,5 & 20 & 0 & 0 & 39 & 1 & 2,6 & 18 & 2 & 11,1 \\
\hline 2010 & 24 & 2 & 8,3 & 22 & 2 & 9,1 & 45 & 4 & 8,9 & 27 & 0 & 0 \\
\hline 2011 & 24 & 1 & 4,2 & 20 & 1 & 5 & 60 & 5 & 8,3 & 27 & 1 & 3,7 \\
\hline Total & 126 & 10 & 7,9 & 104 & 8 & 7,7 & 235 & 19 & 8,1 & 120 & 6 & 5 \\
\hline
\end{tabular}

Fonte: os autores.

Tabela 02: Número de estudos selecionados por evento.

\begin{tabular}{|c|c|c|c|c|c|c|c|c|c|c|c|c|}
\hline \multirow[b]{3}{*}{ Ano } & \multicolumn{12}{|c|}{ Atas de Eventos } \\
\hline & \multicolumn{3}{|c|}{ ENPEC } & \multicolumn{3}{|c|}{$E P E F$} & \multicolumn{3}{|c|}{ ENEQ } & \multicolumn{3}{|c|}{ ENEBIO } \\
\hline & $\mathbf{A P}$ & AT & $\%$ & $\overline{\mathbf{A P}}$ & $\mathrm{AT}$ & $\%$ & $\mathbf{A P}$ & $\mathbf{A T}$ & $\%$ & $\mathbf{A P}$ & AT & $\%$ \\
\hline 2006 & - & - & - & 108 & 5 & 4,6 & 84 & 10 & 11,9 & - & - & - \\
\hline 2007 & 683 & 55 & 8,0 & - & - & - & - & - & - & 237 & 20 & 8,4 \\
\hline 2008 & - & - & - & 165 & 8 & 4,8 & 93 & 19 & 20,4 & - & - & - \\
\hline 2009 & 692 & 53 & 7,6 & - & - & - & - & - & -- & - & - & - \\
\hline 2010 & - & - & - & 131 & 11 & 8,4 & 212 & 32 & 15,1 & 417 & 47 & 11,3 \\
\hline 2011 & 1235 & 118 & 9,5 & 265 & 21 & 7,9 & - & - & - & - & - & - \\
\hline Total & 2610 & 226 & 8,6 & 669 & 45 & 6,7 & 389 & 61 & 15,7 & 654 & 67 & 10,2 \\
\hline
\end{tabular}

Fonte: os autores.

Após a seleção, realizou-se o agrupamento dos trabalhos a partir do referencial teórico que baliza a proposta e uma leitura sistemática e aprofundada dos trabalhos por agrupamento, identificando aqueles que enfocavam práticas desenvolvidas no EM, que totalizou 128 artigos.

\footnotetext{
${ }^{5}$ Número de artigos publicados no ano (AP).

${ }^{6}$ Número de artigo sobre temas localizados com a revisão (AT).
} 
Em função de uma inferência da leitura dos estudos, verificou-se que eles poderiam ser classificados, dependendo de suas características comuns, em Inserção Ampliada ou Inserção Pontual ${ }^{7}$. Entende-se por inserção pontual de temas aquelas que predominantemente focam práticas realizadas em um determinado número de aulas enfocando blocos de conteúdos relacionados a um tema e que apresentam indicativos de cunho metodológico. Já nos estudos agregados no que se chamou de Inserção Ampliada, há um nível de articulação entre a abordagem de temas que acena para mudanças com caráter estrutural no currículo, de forma que as discussões sinalizam transformações que vão além de questões metodológicas a serem implementadas em práticas de sala de aula. O quadro a seguir sintetiza as propostas localizadas.

Quadro 01: Propostas temáticas localizadas com a revisão bibliográfica.

\begin{tabular}{|c|c|c|}
\hline Classificação & Proposta & $\begin{array}{c}\text { Número de trabalhos } \\
\text { selecionados }\end{array}$ \\
\hline \multirow{3}{*}{ Inserção Ampliada } & Tema Estruturador & 09 \\
\cline { 2 - 3 } & Abordagem Temática Freireana & 12 \\
\cline { 2 - 3 } & Enfoque Ciência Tecnologia Sociedade & 20 \\
\cline { 2 - 3 } & Situação de Estudo & 13 \\
\hline Número total de estudos que enfocam Inserção Ampliada & $\mathbf{5 4}$ \\
\hline \multirow{2}{|c|}{} \\
\hline \multirow{3}{*}{ Inserção Pontual } & Ilha Interdisciplinar de Racionalidade & 05 \\
\cline { 2 - 3 } & Unidade de Aprendizagem & 04 \\
\cline { 2 - 3 } & Projeto Temático & 16 \\
\cline { 2 - 3 } & Unidade e Sequência Didática & 47 \\
\cline { 2 - 3 } & Ensino Inovador através de temas & 02 \\
\hline \multicolumn{2}{|c|}{ Número total de estudos que enfocam Inserção Pontual } & $\mathbf{7 4}$ \\
\hline
\end{tabular}

Fonte: os autores.

$\mathrm{Na}$ apresentação dos resultados, a seguir, optou-se pela caracterização das quatro perspectivas de Inserção Ampliada. Também, a título de exemplo do que se denominou de Inserção Pontual, são caracterizadas: Ilha Interdisciplinar de Racionalidade (IIR), Unidade de Aprendizagem (UA) e Projeto Temático ${ }^{8}$. As propostas temáticas foram agrupadas de acordo com o tipo de inserção, ampliada ou pontual, e caracterizadas a partir de dois parâmetros: natureza do tema e função dos conceitos científicos.

\section{Propostas identificadas como Inserção Ampliada}

Tema Estruturador

Localizou-se estudos que abordam práticas implementadas de acordo com o exposto nos PCN+ (BRASIL, 2002), como aqueles que enfocam referenciais curriculares estaduais, em que o currículo foi organizado com base nos Temas Estruturadores, a exemplo do trabalho

\footnotetext{
${ }^{7}$ Termos semelhantes aos utilizados por Watanabe-caramello, Strieder e Gehlen (2012).

${ }^{8}$ A caracterização das demais propostas localizadas com a revisão pode ser encontrada em Halmenschlager (2014). 
sobre a proposta curricular do estado do Rio Grande do Sul (MACKEDANZ et al., 2010), ou nos Eixos Temáticos, como os estudos que discutem aspectos relacionados à reestruturação do currículo das escolas do estado de Minas Gerais (LEAL; MORTIMER, 2008). Contudo, é possível que em outros estados brasileiros isso também tenha ocorrido. De qualquer modo, não estão aqui referenciados porque não foi localizado, com os critérios utilizados para a revisão bibliográfica, nenhum artigo que os enfocasse.

Neste contexto, o estudo de Mackedanz et al. (2010) cita as orientações curriculares do caderno "Lições do Rio Grande"" (RIO GRANDE DO SUL, 2009), apresentando uma investigação acerca das opiniões de professores sobre o desenvolvimento de Temas Estruturadores em sala de aula, além de discutir Unidades Temáticas desenvolvidas por licenciandos de Física, da Universidade Federal do Rio Grande (FURG), na educação básica. Os temas apresentados nos referenciais curriculares são os mesmos daqueles sugeridos pelos $\mathrm{PCN}+{ }^{10}$.

Os temas apresentados no referencial curricular do estado de Minas Gerais são diferentes das temáticas sugeridas nos $\mathrm{PCN}+$. Por exemplo, para o componente curricular de Física, os Conteúdos Básicos Comuns $(\mathrm{CBC})^{11}$ do $1^{\circ}$ ano são trabalhados a partir de três Eixos Temáticos: "Energia e Vida na Terra", "Transferência, Transformação e Conservação da Energia" e "Energia - Aplicações". No componente curricular de Química, os CBC e os Conteúdos Complementares (CC) estão organizados a partir dos eixos "Materiais", "Modelos" e "Energia". Há, ainda, sugestões de temas para o desenvolvimento de projetos, a exemplo das temáticas: "Condições Básicas de Vida", "Águas Usadas: Tratamento de Esgotos", "O Ambiente Modificado" e "Aprofundando o Conhecimento do Planeta". Já o currículo de Biologia do estado de Minas Gerais está organizado a partir de quatro temas, sejam eles: "Teia da Vida", "História da Vida na Terra", "Corpo Humano" e "Saúde". (MINAS GERAIS, 2006).

\footnotetext{
${ }^{9}$ As referidas orientações curriculares estiveram em vigor no período de 2009 a 2011 nas escolas estaduais do Rio Grande do Sul. Em 2012, iniciou-se a implementação de um novo referencial curricular, denominado Ensino Médio Politécnico.

${ }^{10}$ Para o ensino de Física sugerem-se os temas: Movimentos: variações e conservações; Calor, ambiente e usos de energia; Som, imagem e informação; Equipamentos elétricos e telecomunicações; Matéria e radiação; e Universo, Terra e vida. Para o ensino de Química: Reconhecimento e caracterização das transformações químicas; Primeiros modelos de constituição da matéria; Energia e transformação química; Aspectos dinâmicos das transformações químicas; Química e atmosfera; Química e hidrosfera; Química e litosfera; Química e biosfera; Modelos Quânticos e propriedades químicas. Para o ensino de Biologia: Interação entre os seres vivos; Qualidade de vida das populações humanas; Identidades dos seres vivos; Diversidade da vida; Transmissão da vida, ética e manipulação gênica; e Origem e evolução da vida.

${ }^{11}$ Nos referenciais curriculares do estado de Minas Gerais, destaca-se a estrutura para a abordagem dos conteúdos escolares ao longo do ensino médio. No $1^{\circ}$ ano são desenvolvidos os Conteúdos Básicos Comuns (CBC). Esses conteúdos são obrigatórios em toda a rede de ensino. No $2^{\circ}$ e $3^{\circ}$ anos são desenvolvidos os Conteúdos Complementares (CC), em que os CBC devem ser novamente ensinados em um nível maior de aprofundamento, possibilitando aos alunos uma melhor compreensão dos conhecimentos abordados.
} 
No que se refere à natureza do tema, é possível inferir que eles contemplam o que se denominou de natureza conceitual, tanto no referencial curricular "Lições do Rio Grande" quanto no currículo do estado de Minas Gerais. As temáticas agregam, em sua essência, relações diretas com a conceituação científica a ser abordada em sala de aula. Contudo, não foi possível caracterizar as práticas de sala de aula apenas com a análise dos elementos detectados nas publicações localizadas no levantamento realizado. Por exemplo, no caso do referencial curricular para o ensino de Química de Minas Gerais, nos temas sugeridos para o desenvolvimento de projetos, como "Condições Básicas de Vida" e "Águas Usadas: Tratamento de Esgotos" é possível que tenham sido abordadas questões relativas a aspectos sociais, políticos e ambientais. Além disso, as iniciativas de articulação entre os conteúdos escolares e os temas de estudo indicam avanços no tratamento do conhecimento escolar.

No que diz respeito à função dos conceitos científicos, as discussões de Mackedanz et al. (2010) sinalizam que os professores não conseguiram romper com a lógica tradicional de ensino, ou seja, tiveram dificuldades em organizar o processo de ensino e aprendizagem a partir dos Temas Estruturadores, não estabelecendo articulações entre a temática e a conceituação científica. Assim, os conceitos científicos configuraram também o eixo estruturante das atividades planejadas e desenvolvidas.

\section{Abordagem Temática Freireana}

Os estudos que discutem a Abordagem Temática Freireana (ATF), perspectiva temática caracterizada, dentre outros, por Delizoicov (2008), enfocam, principalmente, questões relacionadas à organização curricular a partir de Temas Geradores e da Investigação Temática, com vistas ao desvelamento da realidade pelos estudantes (TORRES; DELIZOICOV, 2007; COELHO; MARQUES, 2007) e à formação docente articulada ao processo de construção curricular (HALMENSCHLAGER et al., 2009). Entre os temas enfocados nos estudos estão: "Mineração do Carvão" (COELHO; MARQUES, 2007), “Tecelagem Manual” (GONDIM, MÓL, 2010), “As águas do Canal da Barra” (TORRES; DELIZOICOV, 2007). Desta forma, a natureza do tema nessa perspectiva educacional envolve o que se denominou de natureza contextual. Nesses casos, a referência principal envolve a problematização de contradições contidas no Tema Gerador, pois o estudo da temática deve possibilitar ao aluno a tomada de consciência acerca da sua realidade com vistas à transformação. Trata-se, pois, de uma perspectiva educacional cuja não-neutralidade é explicitamente considerada na sua articulação com a abordagem de conteúdos científicos, também não-neutros, para a estruturação de currículos e programas de ensino.

Defende-se que a investigação da localidade em que vivem os alunos e a manifestação de problemas relacionados às contradições devem constituir critérios para a escolha desses 
Temas Geradores e para a seleção dos conteúdos universais desenvolvidos em sala de aula. Assim, no que se refere à função dos conceitos científicos, os conteúdos abordados têm a finalidade de auxiliar o aluno na compreensão da temática em estudo, contribuindo para o desenvolvimento do senso crítico e para a superação dos níveis de consciência, em sintonia com a compreensão de Freire (2005), de que a construção do conhecimento, com vistas à transformação, se dá pela superação da consciência real (efetiva) pela consciência máxima possível.

Ao analisar a relação entre o tema e o conteúdo a ser desenvolvido, pode-se afirmar que se busca o estabelecimento de articulações, mediadas por Temas Geradores, entre o contexto sociocultural e os conceitos científicos, possibilitando a significação destes e a abordagem de conteúdos que contemplam aspectos sociais, culturais, ambientais e políticos. Coelho e Marques (2007) discorrem, por exemplo, acerca da temática "mineração do carvão", identificada como significativa no contexto da região de Criciúma (SC), e que possibilita a abordagem de aspectos relativos a poluição do solo e a contaminação de seres humanos. $\mathrm{Ou}$ seja, no que diz respeito à função dos conceitos científicos, nessa proposta a conceituação científica está sempre subordinada ao tema.

Para o desenvolvimento dos temas em sala de aula, destaca-se a concepção de Conceitos Unificadores $^{12}$ (ANGOTTI, 1993) e os Momentos Pedagógicos (MP) ${ }^{13}$ (TORRES; DELIZOICOV, 2007). As atividades propostas em sala de aula, em sintonia com os MP, ao partirem de um problema a ser resolvido, colocam o aluno como sujeito do conhecimento. Portanto, na ATF, o processo de ensino e aprendizagem é organizado tendo como ponto de partida o levantamento das visões de mundo dos estudantes e sua problematização. Essa dinâmica tem por objetivo fazer com que o aluno sinta a necessidade de construir novos conhecimentos, organizados didático-pedagogicamente pelo professor, para melhor compreender o problema posto em discussão.

Com base no exposto, sinaliza-se que a implementação de práticas a partir de Temas Geradores, na perspectiva freireana, permite uma articulação entre temas e conceituação científica, cuja perspectiva não é simplesmente a de se abordar conceitos científicos, mas sim planejar sua abordagem com a finalidade de que eles, ao serem apropriados, possibilitem uma compreensão do tema diferenciada daquela que se tinha, antes desses conceitos terem sido

\footnotetext{
12 São definidos como um conjunto de conceitos que podem se constituir em âncoras na aquisição do conhecimento e como alternativa para minimizar a fragmentação do pensamento, tanto pelos estudantes quanto pelos professores (ANGOTTI, 1993).

${ }^{13}$ Esses momentos correspondem a: 1) Problematização Inicial, que consiste em identificar e problematizar as interpretações que os alunos têm sobre a situação significativa abordada; 2) Organização do Conhecimento, momento em que o professor seleciona quais conhecimentos científicos são pertinentes para dialogar com as questões apontadas pelos alunos e pelo professor; e 3) Aplicação do conhecimento, etapa em que o aluno, de posse do conhecimento científico, faz uso deste para compreender a situação que originou a problematização e estabelecer relações com outras questões que sejam pertinentes.
} 
apropriados pelos alunos. O Tema Gerador não é compreendido somente como um elemento motivador do processo de ensino e aprendizagem, mas como uma situação problema que necessita enfrentamento pela comunidade escolar e que será o ponto de partida e de chegada, onde se pretende que o processo educativo propicie ganhos cognitivos para a compreensão do problema, através de um processo que envolve a construção de conhecimento pelo aluno. Sob essa perspectiva, o conteúdo científico selecionado representa um instrumento para a compreensão do objeto de estudo, estando, obrigatoriamente, a inclusão da conceituação científica escolhida, subordinada ao tema e estruturada com o uso dos Conceitos Unificadores conforme analisam Torres e Delizoicov (2007), Coelho e Marques (2007), em sintonia, portanto, com Delizoicov (2008).

\section{Enfoque CTS}

As propostas de inovações curriculares que buscam aporte nos pressupostos do movimento CTS possuem diferentes níveis de abrangência, pois as iniciativas envolvem, por exemplo, a construção de nova disciplina (SILVA, et al., 2010), o desenvolvimento de projeto (SILVA; MORTIMER, 2007; 2009), e a elaboração de programas de ensino interdisciplinares para a implementação de temáticas de relevância social na Educação de Jovens e Adultos (EJA) (MUENCHEN; AULER, 2007a; 2007b).

Os estudos de Silva e Mortimer (2007, 2009) contemplam o projeto “Água em Foco: qualidade de vida e cidadania", cujo objetivo é possibilitar aos estudantes do EM um ensino de Química contextualizado, que contribua para o entendimento dos fenômenos do mundo. Destaca-se que este projeto promove a integração universidade-escola, sendo trabalhado também na formação inicial de professores de Química, na Universidade Federal de Minas Gerais (UFMG). A elaboração do projeto foi utilizada como meio para a inserção de aspectos que envolvem as relações CTS ao currículo, em que "os temas de trabalho são definidos a partir do diálogo entre o professor e os alunos ou a partir das necessidades do aluno e da comunidade" (SILVA; MORTIMER, 2007, p. 3).

Forgiarini e Auler (2007) e Muenchen e Auler (2007a; 2007b), por sua vez, discorrem sobre a implementação de currículos que tencionam contemplar temáticas sociais relevantes, aproximando as práticas desenvolvidas à abordagem temática na perspectiva freireana. Sob essa ótica, buscam-se "configurações curriculares mais abertas frente a problemas, a temáticas fortemente marcadas pela componente científico-tecnológica" (MUENCHEN; AULER, 2007b, p. 2). Nessa proposta, "os conhecimentos trabalhados deixam de ter um fim em si e/ou apenas uma finalidade futura, passando a constituir-se em meios, em ferramentas para a compreensão de temas de relevância social, para compreensão de situações do mundo vivido" (MUENCHEN; AULER, 2007a, p. 2). 
Entre os temas abordados nos trabalhos estão: "Reflorestamento no RS" (FORGIARINI; AULER, 2007), "Agrotóxicos", "Desmatamento", "Sistema público de saúde" (MUENCHEN; AULER, 2007a), "Metais", "Desperdício" (SANTOS; MORTIMER, 2009) e “Água” (SILVA; MORTIMER, 2007). É possível inferir, portanto, que a natureza do tema nessa perspectiva contempla o que chamou neste estudo de natureza contextual. $\mathrm{O}$ desenvolvimento das temáticas "Reflorestamento no RS" e "Agrotóxicos", por exemplo, de cunho social e político, objetiva que a conceituação científica seja trabalhada de forma que configure instrumento para a compreensão e atuação frente às questões levantadas, vivenciadas pelos alunos. Já os temas "Metais" e "Desperdício", trabalhados a partir do livro Química e Sociedade (SANTOS; MORTIMER, 2009), se relacionarem diretamente com a conceituação específica da Química e com aspectos sociais, ao trazer à discussão, por exemplo, a importância dos metais para o desenvolvimento da civilização e os benefícios e problemas que podem acarretar para a sociedade.

No que se refere à função dos conceitos científicos, as atividades relativas ao tema “Água” visam promover a reflexão acerca da realidade escolar "[...] de forma a possibilitar a mobilização para a mudança social e ambiental e contribuir para a formação de cidadãos críticos e participativos" (SILVA; MORTIMER, 2009, p. 2). Em outro trecho, argumenta-se que propostas que contemplem as relações CTS “[...] podem gerar ações políticas como cartas e abaixo-assinados às autoridades, manifestações como passeatas ou abraço do córrego". Ou seja, intenciona-se que, de posse do conhecimento científico relacionado com o tema em debate, o aluno tenha condições de melhor intervir em sua realidade. No que diz respeito à articulação entre tema e conceituação científica, alguns dos estudos localizados (MUENCHEN; AULER, 2007a; 2007b) defendem a subordinação dos conceitos científicos ao tema, privilegiando uma abordagem interdisciplinar.

Situação de estudo

Os pressupostos da Abordagem Histórico-Cultural, em especial as ideias de Vygotsky, são os principais aportes teóricos da proposta de reconstrução curricular denominada Situação de Estudo (SE) (AUTH et al., 2009; VIANA et al., 2011). De modo geral, a proposta é apresentada como uma alternativa curricular que prioriza uma abordagem não linear e menos fragmentada dos conteúdos de Ciências. A seleção e a organização dos conteúdos a serem estudados estão relacionadas a uma temática que representa uma situação real e que, de alguma forma, se faz presente no contexto dos alunos. Sob essa perspectiva, as SE são elaboradas para serem desenvolvidas no ensino fundamental, em geral, no componente curricular de Ciências, e no EM, envolvendo os componentes curriculares de Física, de Química e de Biologia, configurando-se como um projeto interdisciplinar. 
Na SE, temas como "Conhecendo o câncer: um caminho para a vida" (BOFF et al., 2007), "Drogas - efeitos e consequências no ser humano" (BOFF et al., 2009), "Ar Atmosférico" (LAUXEN et al., 2007) e "Interconversões de energia em processos biofisicoquímicos" (MALDANER; COSTA-BEBER, 2009) são abordados nos trabalhos analisados.

Assim, a natureza do tema na SE assume tanto um viés conceitual quanto um viés contextual. Temáticas como "Interconversões de energia em processos biofisicoquímicos" e "Ar Atmosférico" contemplam o que se denominou de natureza conceitual. Já os temas "Conhecendo o câncer: um caminho para a vida" e "Drogas: efeitos e consequências no ser humano" parecem possuir natureza contextual, envolvendo, de forma especial, aspectos sociais, uma vez que têm como pretensão debater com os alunos efeitos e consequências do uso de drogas, assim como a discussão de fatores que podem contribuir para a diminuição do câncer.

É possível sinalizar que diferentes fatores orientam a escolha dos temas: a) questões relevantes para a comunidade escolar, a exemplo da temática "drogas" que, segundo Boff et al. (2009), foi sugerida pelos estudantes; b) a estrutura conceitual, como na SE intitulada "Interconversões de energia em processos biofisicoquímicos", que, de acordo com Auth et al. (2009, p. 4), “foi proposta e desenvolvida para articular conteúdos da $2^{\text {a }}$ série do ensino médio: termodinâmica, termoquímica, respiração e metabolismo celular, como características dos seres vivos."; e c) temáticas amplamente veiculadas na mídia, como o tema "Aquecimento Global". Conforme explicam Binsfeld e Auth (2009, p. 4), optou-se pela abordagem desse tema "por ser um dos assuntos que mais circulava na mídia e pela potencialidade de ser um contexto vivencial conceitualmente rico para as diversas ciências".

Sobre a função dos conceitos científicos, a própria natureza dos temas indica que a conceituação científica de determinada série pode orientar a escolha do tema, sendo esta realizada, em geral, pelo professor. Em contraposição, entretanto, a discussão realizada em alguns dos estudos localizados na revisão mostra que, embora a estrutura conceitual possa contribuir para a escolha da temática, há flexibilidade para a introdução de novos conteúdos necessários para a compreensão das questões abordadas (BOFF et al., 2007). Ao analisar, por exemplo, as práticas implementadas a partir do tema "Conhecendo o câncer: um caminho para a vida", Boff et al. (2007, p. 6) afirmam que "os conceitos não são definidos previamente por imposição de um programa de ensino, mas são selecionados a partir da necessidade em compreender a SE proposta".

O desenvolvimento da SE visa, portanto, a apropriação do conhecimento por meio de atividades interdisciplinares que promovam, em geral, algum nível de articulação entre contextos e conceituação científica. Essa articulação fica restrita, em alguns trabalhos 
(LAUXEN et al., 2007; MALDANER; COSTA-BEBER, 2009), à proposição de uma problematização que tem como foco a discussão de aspectos contextuais, sem, no entanto, aprofundar questões sociais e políticas mais amplas relacionadas às temáticas em estudo. Essa característica sinaliza que, em relação à função dos conceitos científicos, a apropriação do conhecimento científico na SE está mais relacionada com o entendimento mais amplo de fenômenos, situações e tecnologias, o que contribuiria, na compreensão de seus idealizadores, para o aluno intervir e transformar sua realidade.

\section{Propostas identificadas como Inserção Pontual}

Ilha Interdisciplinar de Racionalidade

As propostas de ensino organizadas como Ilha Interdisciplinar de Racionalidade (IIR) têm como aporte teórico as ideias de Fourez et al. (1997), que discutem a Alfabetização Científica e Tecnológica (ACT), defendendo que, para que a mesma ocorra, o processo de ensino e aprendizagem deve proporcionar a um indivíduo autonomia, capacidade de comunicação e domínio do conhecimento. Como metodologia de ensino, apresentam a IIR, que pode ser desenvolvida em torno de um projeto, de uma noção ou de uma tecnologia, enfocando, dessa forma, temas que permitem estabelecer relações entre o conteúdo científico e a situação em estudo.

Os temas abordados na IIR apresentam distintos enfoques, a exemplo do tema "Automedicação" (RICHETTI; ALVES-FILHO, 2010), que configura um tema social; do tema "Reciclagem do lixo urbano" (SOUSA; BRITO, 2007), voltado para a questão ambiental; e do tema "Nanociência e Nanotecnologia" (LEONEL; SOUZA, 2009), que caracteriza um enfoque tecnológico envolvendo a conceituação científica.

A natureza do tema na IIR abrange, portanto, principalmente, o que se chamou de natureza contextual. A temática "Reciclagem do lixo urbano" (SOUZA; BRITO, 2007), por exemplo, permitiu explorar aspectos como poluição do solo e das águas, a legislação municipal e estadual referente ao processo de coleta e destino do lixo, mercado de trabalho, entre outros. As discussões em torno desses aspectos contemplaram aspectos sociais e ambientais. Richetti e Alves Filho (2010) destacam que o tema "automedicação" possibilita explorar aspectos relacionados, conforme denominam os autores, à dimensão familiar e social, à dimensão cultural, à dimensão econômica e à dimensão política. Essa metodologia pode ser considerada um modelo para representar situações do cotidiano dos alunos, configurando uma estratégia pedagógica e epistemológica que permite abordar o conhecimento proveniente de várias disciplinas e também os conhecimentos prévios dos estudantes (RICHETTI; ALVES FILHO, 2010). Contudo, parece que cabe ao aluno buscar e articular informações provenientes de distintas áreas do saber para melhor compreender o 
tema em estudo. E o professor assume mais o papel de mediador no desenvolvimento das etapas da IIR do que estruturador de atividades interdisciplinares.

Reconhece-se a importância de trabalhar a partir de situações que tenham algum significado ao estudante, muito embora essa situação não represente, necessariamente, um problema, uma contradição que pode ser superada. Isso permite inferir que, apesar do aluno participar ativamente das decisões acerca do tema a ser estudado e das estratégias a serem realizadas para buscar as informações necessários para o entendimento da temática, o processo de construção do conhecimento no desenvolvimento de uma IIR tem múltiplas possibilidades para o ponto de partida, conforme as situações referidas. Contudo, parece não haver critérios que orientem a seleção das Ilhas de Racionalidade na sua relação com uma problemática proveniente de contradições, ainda que isso possa ocorrer. Sua escolha parece ser balizada pela necessidade de possibilitar a busca de informações, pelos alunos, oriundas de várias áreas do conhecimento para a sua melhor compreensão. A dimensão problematizadora ficaria, então, na dependência da perspectiva metodológica durante o seu desenrolar.

No que refere à função dos conceitos científicos, os conteúdos a serem ensinados determinam, em geral, a escolha da temática. Neste sentido, Richetti e Alves Filho (2010, p. 5) explicam que "a temática da Automedicação foi escolhida pela sua estreita relação com os conteúdos de Química e também por ser uma prática comum no cotidiano da população brasileira". Leonel e Souza (2009) também apontam para a importância de discussão do tema "Nanociência e Nanotecnologia" no EM como forma de contemplar conteúdos de Física Moderna e Contemporânea, muitas vezes negligenciados na educação básica.

No entanto, apesar do potencial da IIR para a significação de um determinado tema e dos conteúdos relacionados a ele, as discussões acerca da elaboração e implementação contemplam, de maneira quase exclusiva, o viés metodológico para o desenvolvimento da IIR escolhida para compreensão. Através da análise dos estudos localizados não foi possível detectar articulações mais orgânicas com o processo educativo, além daquele que organiza procedimentos de orientação para os alunos. Por exemplo, não há referência a ações realizadas junto a secretarias de educação e de forma mais sistemática em escolas, em parceria com professores do ensino básico. Os trabalhos analisados não se ocuparam em explicitar relações entre o que se propõe desenvolver a partir da IIR e a necessidade de um processo formativo contínuo com os docentes da educação básica, a exemplo do que se promove na SE (BOFF et al., 2007) e em processos implementados por secretarias de educação que optaram por um currículo estruturado em Temas Geradores (DELIZOICOV, 2008; SILVA, 2004). 
Unidade de Aprendizagem

A Unidade de Aprendizagem (UA) é apresentada como uma metodologia, organizada a partir de temas, que tem por objetivo superar o planejamento sequencial que consta, em especial, nos livros didáticos e currículos tradicionais. Busca-se valorizar o conhecimento prévio dos alunos, para, a partir das atividades realizadas, possibilitar a (re)construção de conceitos (LARA et al., 2007; DUSO et al., 2010). Essa perspectiva está balizada, principalmente, nos princípios do Educar pela Pesquisa (DEMO, 2011).

As atividades propostas contemplam temas que apresentam uma natureza conceitual, como a temática "Soluções", discutida por Lara et al. (2007). Os autores destacam diversos aspectos que permitem estabelecer relações entre o tema "Soluções" e o contexto dos alunos, a exemplo do fato de as soluções estarem presente na vida diária (remédio, produtos de higiene e limpeza) e da degradação que podem causar ao meio ambiente (poluição, doenças), enfatizando a abordagem do tema a partir dos conceitos a serem estudados. Destaca-se o tema "Nanotecnologia e Saúde", enfocado por Duso et al. (2010) que, além de abordar conceitos relacionados à nanotecnologia, possibilitou discutir sobre o tratamento e a prevenção de doenças por meio da nanomedicina.

Com base nisso, é possível sinalizar, no que diz respeito à função dos conceitos científicos, que na relação entre tema e conteúdo há uma subordinação das temáticas aos conceitos, sendo que, de maneira geral, o conteúdo/conceito em si é entendido como um tema. Desta forma, a conceituação científica configura critérios para a escolha do tema.

Metodologicamente, a UA é organizada a partir de três pressupostos: questionamento, construção de argumentos e comunicação ${ }^{14}$ (LARA et al., 2007). Para contemplá-los, diversas atividades são desenvolvidas com os alunos, como debates, pesquisas, seminários, uso de software, produção escrita, aula expositiva dialogada, jogos educativos, resolução de exercícios, elaboração de projetos de pesquisa, entre outras.

O processo de construção do conhecimento inicia a partir do questionamento, o qual não representa um problema que necessita enfrentamento, pois envolve, principalmente, dúvidas e curiosidades acerca da temática, tendo como função possibilitar o levantamento das concepções prévias dos alunos. Ou seja, no desenvolvimento da UA em sala de aula, o aluno é desafiado a ser ator no processo de aprendizagem, muito embora o que se chama de questionamento não configure uma problematização do tema e dos conhecimentos prévios identificados.

\footnotetext{
${ }^{14} \mathrm{O}$ questionamento pode envolver qualquer aspecto relacionado ao ser, como conhecimentos, valores, atitudes, etc. A etapa de construção de argumentos, por sua vez, implica na participação ativa e reflexiva do aluno, exigindo análise, interpretação e novas compreensões sobre o tema em estudo. Por fim, segue-se a etapa da comunicação, em que os resultados da pesquisa são socializados e postos em discussão (LARA et al., 2007).
} 
Práticas interdisciplinares também são defendidas e apresentadas nos trabalhos. Duso et al. (2010) relatam que o desenvolvimento da UA sobre "Nanotecnologia e Saúde" envolveu os componentes curriculares de Química, Física, Matemática, Língua Portuguesa, Biologia, Informática Básica e Artes. Lara et al. (2007) discutem a UA desenvolvida na disciplina de Química, mas chamam a atenção para o caráter interdisciplinar dessa proposta, pois ela "reúne as concepções do saber científico, saberes culturais, crenças, ideologias, e outros, possibilitando uma visão global do conhecimento humano, tornando possível que o aluno se torne sujeito de suas ações" (LARA et al., 2007, p. 5).

Na UA há maior ênfase no desenvolvimento de atividades com o objetivo de estabelecer novas relações entre o conteúdo, o estudante e o professor, em que o compromisso com a aprendizagem é compartilhado. Isso implica na adoção, pelo professor, escola e aluno, de outra postura diante do que deve ser ensinado e aprendido, superando a mera transmissão de informações. Argumenta-se, na UA, em favor da importância da pesquisa na escola em sintonia com Demo (2011). No entanto, essa nova postura parece mais relacionada com "como ensinar" do que com "o que ensinar" e "para que ensinar". Em outras palavras, embora a UA organize o desenvolvimento das aulas a partir de uma temática, parece que, fundamentalmente, sua ênfase está na participação ativa do estudante na escolha e no desenvolvimento das questões abordadas em sala, de forma que seus interesses, dúvidas e questionamentos sejam debatidos. Neste caso, o tema e o próprio conteúdo seriam subordinados a esses parâmetros metodológicos. Porém, cabe destacar que a proposta apresenta importantes aspectos que permitem avançar na abordagem de temas, a exemplo da importância da pesquisa em sala de aula.

\section{Projeto Temático}

Os Projetos Temáticos discutidos no âmbito da pesquisa em ensino de Ciências apresentam distintos referenciais teóricos, a exemplo de Duso e Borges (2007) que enfocam o projeto "Aquecimento Global: motores e suas influências na poluição e Meio Ambiente", em que a temática principal é o "Aquecimento Global", balizado na ideia de Pedagogia de Projetos (HERNÁNDEZ, 1998).

Santos et al. (2010) destacam a importância da abordagem CTS no projeto de extensão “A Química vai à escola: preparação e apresentação de palestras e experimentos para alunos do ensino médio", promovido pela Universidade Federal de Goiás (UFG). No referido projeto, o tema "Lixo" é desenvolvido com o objetivo de que os alunos compreendam as relações existentes entre o conteúdo químico e situações do cotidiano. Na mesma direção, Gomide et al. (2010) discorrem acerca do projeto interdisciplinar, que contempla a perspectiva CTS, sobre o tema "Bronzeamento Artificial". As atividades desenvolvidas 
envolveram os componentes curriculares de Física, Química, Biologia, Sociologia, Geografia e Língua Portuguesa.

Destacam-se também os projetos que buscam aporte teórico na abordagem construtivista e nas orientações dos PCN, alguns enfocando, inclusive, os dois referenciais. Por exemplo, Papoula et al. (2008) apresentam discussões realizadas acerca de um projeto sobre o tema "Água e Saúde”, a partir das ideias de Piaget e de Vygotsky; e Costa e Carvalho (2009) discorrem sobre o projeto "A educação ambiental, lixo e reciclagem: mudanças de atitudes no contexto escolar e na comunidade", que buscam referência nos PCN, em Vygotsky e em Ausubel.

Diante dos temas contemplados nos projetos citados anteriormente, é possível inferir que muitos projetos enfocam, principalmente, Temas Transversais (BRASIL, 1997), discutindo questões sobre saúde e ambiente. Em geral, os temas foram selecionados por permitirem uma aproximação do conhecimento científico ao contexto do aluno, ou seja, os projetos foram desenvolvidos para contemplar, de forma contextualizada e interdisciplinar, os conteúdos escolares. A natureza do tema nos Projetos Temáticos contempla, de modo geral, o que se denomina de natureza contextual, e envolve, principalmente, questões socioambientais. Afirma-se, no material analisado, que por meio da abordagem de temas dessa natureza, buscase desenvolver o senso crítico nos estudantes, com vistas à conscientização acerca dos problemas ambientais, das relações CTS e suas implicações na vida diária, entre outros.

No que se refere a questões metodológicas, há uma maior ênfase para as estratégias didáticas desenvolvidas a partir da temática em questão. Os estudos, em sua maioria, justificam a escolha da temática em função de sua relevância social e/ou ambiental e sua relação com o conteúdo, o que permite concluir que os temas são escolhidos pelos professores, em alguns casos, na interação com as universidades. Entre as estratégias de ensino explicitadas estão: pesquisa de campo, entrevistas, debates, jogos de papéis, exibição de filmes e documentários, construção de maquetes, seminários, atividades experimentais, aulas expositivas.

As atividades propostas aos alunos nos trabalhos localizados, no entanto, usam, em sua maioria, o tema como ilustração dos conteúdos a serem estudados. Assim, o contexto expresso a partir da temática é explorado com a finalidade de se abordar os conceitos científicos, permanecendo, segundo parece, como uma motivação para introduzi-los na programação. Em geral, o tema parece ser apresentado ao aluno pelo professor, sem, aparentemente, enfatizar o caráter problematizador envolvido nas questões levantadas.

De acordo com os trabalhos analisados, os projetos temáticos não implicam em mudanças na estrutura curricular das disciplinas envolvidas, estando voltados mais para a discussão de temáticas que possuem relação muito próxima com o conteúdo escolar, ao 
mesmo tempo em que contribuem para a inserção de elementos contextuais. Destaca-se que as propostas de projetos têm, geralmente, como componente curricular central, a Biologia.

Em relação à função dos conceitos científicos, a apropriação do conhecimento pode permitir ao aluno relacionar os conteúdos escolares com os contextos enfocados em sala de aula. Contudo, as práticas descritas nos trabalhos analisados remetem, em sua maioria, para a ilustração de conceitos científicos a partir dos temas, através das opções metodológicas dos projetos que, nem sempre, se relacionam com uma perspectiva explícita de transformação do contexto considerado, através de problematizações, ainda que priorizem planejar ações com o objetivo de propiciar que o aluno aprenda a aprender.

\section{Considerações finais}

Ainda que o levantamento realizado para se mapear as iniciativas pioneiras de implementação de abordagem de temas contemple um período relativamente curto, de 2006 a 2011, quando comparado com o período decorrido entre o momento atual e as primeiras publicações do MEC (BRASIL, 2000) referentes aos parâmetros curriculares do EM, a análise dos estudos parece indicar tentativas de se construir opções de uma perspectiva curricular que articule temas e conceituação científica, em particular na atuação de pesquisadores em Educação em Ciências, nas relações que estabelecem com os distintos atores e instituições que se dedicam à educação escolar. Também parece sintomático que outra compreensão (ou outras compreensões) de conteúdo escolar esteja emergindo. Mesmo que seja prematuro uma caracterização dessa(s) nova(s) concepção(ões) que está(ão) emergindo para o termo conteúdo, há indícios que ele não se reduz à perspectiva curricular que têm por parâmetros apenas estruturas conceituais disciplinares. Conforme se evidenciou, a conceituação científica presente nessas estruturas foram contempladas nas distintas iniciativas de Abordagem Temática analisadas. Contudo, o termo que poderíamos denominar de conteúdos escolares já não se resume a uma listagem de conceitos científicos apresentados em programas de ensino de disciplinas. Trata-se da emergência do que Snyders (1988) denomina de conteúdos escolares renovados.

É significativa, também, a crescente adequação dos livros didáticos destinados ao EM com a perspectiva de apresentar conteúdos renovados. Os resultados das análises desses livros, realizadas no âmbito do Programa Nacional do Livro Didático (PNLD), vêm detectando essa adequação, fomentada por editais do MEC para a adoção das obras didáticas que serão destinadas às escolas públicas. O Guia do Livro Didático oriundo da análise de avaliadores, especialistas em cada uma das disciplinas que constituem o currículo do EM, têm dado ênfase nas orientações aos professores sobre a emergência de outras compreensões para o termo conteúdo escolar. O Guia do Livro Didático de Física, por exemplo, destaca: 


\begin{abstract}
A Física escolar deve contemplar [...] não só a escolha cuidadosa dos elementos principais mais importantes, presentes na estrutura conceitual da Física como uma disciplina científica, uma área do conhecimento sistematizado, em termos de conceitos e definições, princípios e leis, modelos e teorias, fenômenos e processos; mas deve também incorporar um tratamento articulado desses elementos entre si e com outras áreas disciplinares, bem como com aspectos históricos, tecnológicos, sociais, econômicos e ambientais, de modo a propiciar as aprendizagens significativas necessárias aos alunos, e, assim, contribuir para que o ensino médio efetive sua função como etapa final da formação educacional básica de todo e qualquer cidadão (BRASIL, 2014, p. 10).
\end{abstract}

Assim, é na perspectiva dos conteúdos renovados, na sua relação tanto com currículos escolares quanto nas abordagens em sala de aula, que podemos vislumbrar os trabalhos considerados no levantamento realizado e tentativamente esboçar uma síntese. Obviamente, uma síntese parcial e provavelmente sujeita a alterações, uma vez que muito do que possa ter sido publicado em revistas e anais, após 2011, não foi foco da pesquisa realizada. É pertinente, contudo, supor que iniciativas pioneiras, tais como as apresentadas neste artigo, possam ter tido influências em trabalhos posteriores.

A análise realizada indicou a existência de diferentes compreensões acerca da Abordagem Temática no ensino de Ciências, predominando o estudo de temas de natureza contextual. Contudo, foram localizados relativamente poucos estudos que têm como objetivo apresentar e discutir temáticas que representem um problema ou uma contradição que necessite enfrentamento. A conceituação científica, por sua vez, orienta a escolha das temáticas em algumas das propostas analisadas, a exemplo da UA e da IIR, na implementação pontual, e de algumas SE, que buscam a reconfiguração curricular. Isso sinaliza para a necessidade de ampliar as discussões em torno dos critérios de seleção dos temas, de modo que alternativas, além das que se apresentam como determinadas pela própria conceituação, e, portanto, subordinadas a elas, possam subsidiar também propostas de Abordagem Temática como determinantes da seleção de conceito.

Mais da metade $(57,8 \%)$ dos trabalhos localizados com a revisão integra uma perspectiva de Inserção Pontual. Essas iniciativas ocorrerram em algumas aulas, atendendo, de modo geral, a um determinado bloco de conceitos científicos, como na UA e na IIR. Parece, portanto, que a implementação de práticas que caracterizam, em especial, Inserção Ampliada, numa perspectiva de reconfiguração curricular, para além de aspectos relativos ao tratamento didático-pedagógico de conceituação científica e às relações professor-aluno representa, ainda, um desafio, mesmo que se leve em conta que uma caminhada neste sentido já se iniciou. Destaca-se duas perspectivas que vêm enfrentando esse desafio:a ATF e a SE. Diante disso, considera-se pertinente aprofundar as compreensões acerca dos encaminhamentos necessários para a implementação de propostas temáticas que tenham como objetivo a reorganização curricular a partir de temas significativos para a comunidade escolar, que abarcam, além de elementos oriundos do conhecimento produzido pelas ciências da 
natureza, tais como suas estruturas conceituais, e muitas vezes apenas estas como referência para o ensino de disciplinas escolares, aspectos contextuais, sociais, ambientais e/ou políticos.

Não obstante, os resultados apresentados no presente artigo, embora parciais e sujeitos a alteração com a ampliação da revisão bibliográfica, indicam que o desafio da renovação dos conteúdos escolares por meio da abordagem de temas vem sendo enfrentado a partir de, pelo menos, quatro maneiras distintas, quais sejam: (i) Inserção Pontual Conceitual; (ii) Inserção Pontual Contextual; (iii) Inserção Ampliada Conceitual; (iv) Inserção Ampliada Contextual. Uma proposta conceitual, seja Pontual ou Ampliada, está estruturada a partir de uma escolha, cuja temática se origina explicitamente da natureza conceitual das ciências, ou mesmo de um conceito em si, sendo este o ponto de partida para a organização das atividades. Já uma proposta contextual tem como ponto de partida para a organização das atividades de ensino um contexto, o qual pode contemplar distintos aspectos, como fenômenos naturais e tecnológicos, situações problemas e aspectos relativos ao ambiente, e cuja escolha não se restringe originalmente a um ou mais conceitos científicos específicos, ainda que conceitos científicos específicos sejam incluídos na programação de ensino.

Desta maneira, práticas educativas elaboradas a partir de temas de natureza conceitual e que tenham como proposta a inserção pontual, como a UA, estariam alocadas na perspectiva chamada de Inserção Pontual Conceitual. Já quando as temáticas abordam a natureza contextual, a exemplo de trabalhos desenvolvidos a partir de Projetos Temáticos, as práticas estariam alinhadas com a perspectiva Inserção Pontual Contextual. De forma semelhante, propostas de ensino organizadas a partir de temáticas cuja natureza se enquadra no que se denominou de natureza contextual que tenham como objetivo a reconstrução curricular, como a ATF, estariam em sintonia com a perspectiva de Inserção Ampliada Contextual. Quando, apesar de prever a reconstrução curricular, as práticas analisadas e/ou sugeridas estiverem pautadas em temas de natureza conceitual, a exemplo de algumas SE, contemplaria a perspectiva de Inserção Ampliada Conceitual. Assim, conforme Halmenschlager (2014), a caracterização das propostas indica, ainda, que as práticas implementadas por meio de temáticas podem ser associadas a um "espectro", de modo semelhante ao procedimento adotado por Sauerwein e Delizoicov (2008) para caracterizar o perfil de concepções de formação continuada de professores física. Trata-se de uma gradação segundo a qual às opções de se organizar a formação continuada de professores são representadas conforme as distintas concepções históricas de formação ou, no caso deste artigo - que diz respeito a um ensino tendo temáticas como parâmetros - distintas concepções de currículo, quando se pretende organizar um ensino de modo a articular contextualização e conceituação científica através de uma abordagem de temas. A gradação representada por esse "espectro" seria, então, indicativa da posição relativa de currículos assim concebidos, segundo sua maior ou 
menor aproximação, com as quatro maneiras, abstraídas neste artigo, de se organizar a abordagem de temas com a articulação contextos e conceitos.

Por fim, considera-se fundamental investigar como as propostas aqui apresentadas estão se transformando em prática docente no contexto escolar. Para melhor compreender em que medida ocorre a superação da linearidade e da fragmentação no trabalho efetivo da sala de aula, em qualquer uma dessas perspectivas de inserção de temas, e também quais elementos são fundamentais para a adoção de outras referências, que não somente os conceitos científicos, para a organização de propostas de ensino pautadas em temáticas.

\section{Referências}

ANGOTTI, J A. P. Conceitos unificadores e ensino de física. Revista Brasileira de Ensino de Física, v. 15, nº (1 a 4), p. 191 - 198, 1993.

AUTH, M. A.; PANSERA-DE-ARAÚJO, M. C.; MALDANER, O. A.; COSTA-BEBER, L. B.; MACHADO, A. R. Currículo por área de conhecimento no ensino médio: possibilidades criadas com situações de estudo nas ciências da natureza. In: ENCONTRO NACIONAL DE PESQUISA EM EDUCAÇÃO EM CIÊNCIAS, 7., Florianópolis. Anais...Florianópolis, 2009.

BINSFELD, S. C.; AUTH, M. A. A presença da divulgação científica no processo de ensinoaprendizagem do nível médio. In: ENCONTRO NACIONAL DE PESQUISA EM EDUCAÇÃO EM CIÊNCIAS, 7., Florianópolis. Anais...Florianópolis, 2009.

BOFF, E. T. O.; FRISON, M. D.; SILVA, V. P.; LOTTERMANN, C. L.; PINO, J. C. Situação de estudo: uma possibilidade de reconstrução de teorias e práticas docentes. In: ENCONTRO NACIONAL DE PESQUISA EM EDUCAÇÃO EM CIÊNCIAS, 6. Florianópolis. Anais...Florianópolis, 2007.

BOFF, E. T. O.; SOARDI, T. W.; PANSERA-DE-ARAÚJO M. C.; DEL PINO, J. C. Drogas: Uma Proposta de Organização Curricular que articula Formação Docente. In: ENCONTRO NACIONAL DE PESQUISA EM EDUCAÇÃO EM CIÊNCIAS, 7., Florianópolis. Anais...Florianópolis, 2009.

BRASIL. Secretaria de Educação Fundamental. Parâmetros curriculares nacionais: introdução aos parâmetros curriculares nacionais. Brasília: MEC/SEF, 1997.

BRASIL. Ministério da Educação. Parâmetros Curriculares Nacionais Ensino Médio: Parte I - Bases Legais. Brasília: MEC/SEMTEC, 2000.

BRASIL. Ministério da Educação. PCN+ Orientações Educacionais Complementares aos Parâmetros curriculares Nacionais - Ciências da Natureza, Matemática e suas Tecnologias. Brasília: MEC/SEMTEC, 2002.

BRASIL. Ministério da Educação. Orientações Curriculares para o Ensino Médio: Ciências da Natureza, Matemática e suas Tecnologias. Brasília: MEC/SEB, 2006.

BRASIL. Ministério da Educação. Programa Ensino Médio Inovador. Brasília: MEC/SEB, 2013. 
BRASIL. Guia de livros didáticos: PNLD 2015: física: ensino médio. Brasília: MEC/SEB, 2014.

COELHO, J. C.; MARQUES, C. A. Contribuições freireanas para a contextualização no ensino de Química. Ensaio: Pesquisa em Educação em Ciências, Belo Horizonte, v. 9, n. 1, p. $1-17,2007$.

COSTA, P. C. F.; CARVALHO, E. S. Os conceitos de lixo, reciclagem e meio ambiente e a aprendizagem significativa em uma amostra de alunos de um projeto de educação ambiental. In: ENCONTRO NACIONAL DE PESQUISA EM EDUCAÇÃO EM CIÊNCIAS, 7., Florianópolis. Anais...Florianópolis, 2009.

DELIZOICOV, D. Conhecimento, Tensões e Transições. Tese de doutorado em Educação Universidade de São Paulo, São Paulo, 1991.

DELIZOICOV, D. La Educación em Ciências y La Perspectiva de Paulo Freire. Alexandria Revista de Educação em Ciências e Tecnologia, v. 1, n. 2, p .37-62, 2008.

DEMO, P. Educar pela pesquisa. Campinas: Autores Associados, 2011.

DUSO, L.; BORGES, R. M. R. Projeto integrado sobre aquecimento global e mudança de postura dos aprendentes. In: ENCONTRO NACIONAL DE PESQUISA EM EDUCAÇÃO EM CIÊNCIAS, 6., Florianópolis. Anais...Florianópolis, 2007.

DUSO, L.; DA-BROI, M. P.; CUNHA, P. F. V. Atividade interdisciplinar sobre temas atuais no ensino de ciências. In: ENCONTRO NACIONAL DE ENSINO DE BIOLOGIA \& ENCONTRO REGIONAL DE ENSINO DE BIOLOGIA (Regional 5), 3., Fortaleza. Anais...Fortaleza, 2010.

FERREIRA, N. S. A. As pesquisas denominadas estado da arte. Educ. Soc., v. 23, n. 79, p. 257-272, 2002.

FORGIARINI, M. S.; AULER, D. A abordagem de temas polêmicos no currículo da EJA : o caso do "florestamento" no RS. In: ENCONTRO NACIONAL DE PESQUISA EM EDUCAÇÃO EM CIÊNCIAS, 6., Florianópolis. Anais...Florianópolis, 2007.

FOUREZ, G.; ENGLEBERT-LECOMPTE, V.; GROOTAERS, D.; MATHY, P.; TILMAN, F. Alfabetización Científica y Tecnológica. Acerca de las finalidades de la enseñanza de las ciencias. Argentina: Ediciones Colihue, 1997.

FREIRE, P. Pedagogia do Oprimido. Rio de Janeiro: Paz e Terra, 2005.

GOMIDE, H. A.; LIMA, S. C.; TAKAHASHI, E. K. Bronzeamento artificial: uma proposta metodológica dialogando com a educação, ciência e sociedade. In: ENCONTRO NACIONAL DE ENSINO DE BIOLOGIA \& ENCONTRO REGIONAL DE ENSINO DE BIOLOGIA (Regional 5), 3., Fortaleza. Anais...Fortaleza, 2010.

GONDIM, M. S. C.; MÓL, G. S. Saber popular e ensino de ciências: possibilidades para um trabalho interdisciplinar. In: ENCONTRO NACIONAL DE ENSINO DE QUÍMICA, 15., Brasília. Anais...Brasília, 2010. 
HALMENSCHLAGER, K. R. Abordagem de temas em Ciências da Natureza no Ensino Médio: implicações na prática e na formação docente. Tese de doutorado em Educação Científica e Tecnológica - Universidade Federal de Santa Catarina, Florianópolis, 2014.

HALMENSCHLAGER, K. R. Abordagem Temática no Ensino de Ciências: Algumas Possibilidades. Vivências: Revista Eletrônica de Extensão da URI. v. 7, n. 13, p. 10- 21, 2011.

HALMENSCHLAGER, K. R.; STUANI, G. M.; SOUZA, C. A. A situação de estudo e a investigação temática como possibilidade de formação continuada. In: ENCONTRO NACIONAL DE PESQUISA EM EDUCAÇÃO EM CIÊNCIAS, 7., Florianópolis. Anais...Florianópolis, 2009.

HERNÁNDEZ, F. Transgressão e mudança na Educação: os projetos de trabalho. Porto Alegre: Artmed, 1998.

LARA, J. I. M.; BORGES, R. M. R.; BASSO, N. R. S. Unidade de Aprendizagem sobre soluções: Avaliação de uma proposta interativa de educação química. In: ENCONTRO NACIONAL DE PESQUISA EM EDUCAÇÃO EM CIỂNCIAS, 6., Florianópolis. Anais...Florianópolis, 2007.

LAUXEN, M. T.; WIRZBICKI, S. M.; ZANON, L. B. O desenvolvimento de currículo de Ciências Naturais no Ensino Médio numa abordagem contextual e interdisciplinar. In: ENCONTRO NACIONAL DE PESQUISA EM EDUCAÇÃO EM CIÊNCIAS, 6. Florianópolis. Anais...Florianópolis, 2007.

LEAL, M. C.; MORTIMER, E. F. Apropriação do discurso de inovação curricular em química por professores do ensino médio: perspectivas e tensões. Ciência \& Educação, v.14, n.2, p. 213-231, 2008.

LEONEL, A. A.; SOUZA, C. A. Nanociência e nanotecnologia para o ensino de Física moderna e contemporânea na perspectiva da alfabetização científica e técnica. In: ENCONTRO NACIONAL DE PESQUISA EM EDUCAÇÃO EM CIÊNCIAS, 7., Florianópolis. Anais...Florianópolis, 2009.

LÜDKE, M.; ANDRÉ, M.E.D.A. Pesquisa em Educação: Abordagens Qualitativas. São Paulo: Ed. Pedagógica e Universitária - EPU EPU, 1986.

MACKEDANZ, L.F.; ARAÚJO, R. R.; SILVA, G.R; SANTANA, R.C. Temas Estruturadores em sala de aula: o desafio da contextualização no ensino de Física. In: ENCONTRO DE PESQUISA EM ENSINO DE FÍSICA, 12., Águas de Lindóia. Anais...Águas de Lindóia, 2010.

MALDANER, O. A.; COSTA-BEBER, L. B. Recontextualização de conteúdos científicos escolares por meio de situações de estudo: mapa metaconceitual. In: ENCONTRO

NACIONAL DE PESQUISA EM EDUCAÇÃO EM CIÊNCIAS, 7., Florianópolis. Anais...Florianópolis, 2009.

MINAS GERAIS. Secretaria de Estado da Educação. Proposta curricular CBC - Plano curricular do Ensino Médio. Belo Horizonte: SEE, 2006.

MUENCHEN, C.; AULER, D. Configurações Curriculares Mediante o Enfoque CTS: desafios a serem enfrentados na Educação de Jovens e Adultos. Ciência \& Educação, Bauru, v. 13. n. 3, p. 421-434, 2007a. 
MUENCHEN, C.; AULER, D. Abordagem Temática: desafios na educação de jovens e adultos. Revista Brasileira de Pesquisa em Educação em Ciências, v. 7, n. 3, p. 1-17, 2007b.

PAPOULA, N. R. P. R.; ASSIS, S. S.; BORGES, J. N.; SANTIAGO, C.; TEIXEIRA, G. A. P. B. Água e Saúde. In: ENCONTRO NACIONAL DE ENSINO DE BIOLOGIA \& I ENCONTRO REGIONAL DE ENSINO DE BIOLOGIA (Regional 04), 2., Uberlândia. Anais...Uberlândia, 2007.

RICHETTI, G. P.; PINHO-ALVES, J. Unindo as peças do quebra-cabeça: a automedicação no Ensino de Química à luz da Alfabetização Científica e Tecnológica. In: ENCONTRO NACIONAL DE ENSINO DE QUÍMICA, 15., Brasília. Anais...Brasília, 2010.

RIO GRANDE DO SUL. Secretaria da Educação. Referencial curricular Lições do Rio Grande - Ciências da Natureza e suas Tecnologias. Porto Alegre, Secretaria da Educação, 2009.

SANTOS, D. G.; BORGES, A. P. A.; BORGES, C. O.; MARCIANO, E. P.; BRITO, L. C.C.; CARNEIRO, G. M. B.; NUNES, S. M. T. A Química do Lixo: utilizando a contextualização no ensino de conceitos químicos. . In: ENCONTRO NACIONAL DE ENSINO DE QUÍMICA, 15., Brasília. Anais...Brasília, 2010.

SANTOS, W. L.; MORTIMER, E. F. Aspectos sociocientíficos em aulas de Química. Investigações em Ensino de Ciências, v. 14, n. 2, p. 191-218, 2009.

SAUERWEIN, I. P. S; DELIZOICOV, D. Formação continuada de professores de física do ensino médio: concepções de formadores. Caderno Brasileiro de Ensino de Física, Florianópolis, v. 25, n. 3: p. 439-477, 2008.

SILVA, K. M. A.; FARIA, R. L.; FREITAS, E. C.; SHUVARTZ, M. Teia Viva: uma proposta na ressignificação curricular no ensino de Biologia. In: ENCONTRO NACIONAL DE ENSINO DE BIOLOGIA \& ENCONTRO REGIONAL DE ENSINO DE BIOLOGIA (Regional 5), 3., Fortaleza. Anais...Fortaleza, 2010.

SILVA, A. F. G. A construção do currículo na perspectiva popular e crítica: das falas significativas às práticas contextualizadas. Tese de doutorado em Educação - Pontifícia Universidade Católica de São Paulo, São Paulo, 2004.

SILVA, P. S.; MORTIMER, E. F. Projeto água em foco, qualidade de vida e cidadania: uma experiência na formação inicial de professores. In: ENCONTRO NACIONAL DE PESQUISA EM EDUCAÇÃO EM CIÊNCIAS, 6., Florianópolis. Anais...Florianópolis, 2007.

SILVA, P. S.; MORTIMER, E. F. O Projeto Temático na sala de aula: Mudanças nas interações discursivas. In: ENCONTRO NACIONAL DE PESQUISA EM EDUCAÇÃO EM CIÊNCIAS, 7., Florianópolis. Anais...Florianópolis, 2009.

SNYDERS, G. A alegria na escola. São Paulo: Ed. Manole, 1988.

SOUSA, R. G.; BRITO, L. P. Desafios de uma prática CTS construída a partir de uma Ilha de Racionalidade sobre a reciclagem do lixo urbano. In: ENCONTRO NACIONAL DE PESQUISA EM EDUCAÇÃO EM CIÊNCIAS, 6., Florianópolis. Anais...Florianópolis, 2007. 
STRIEDER, R. B.; CARAMELLO, G. W.; GEHLEN, S. T. Abordagem de Temas no Ensino Médio: compreensões de professores de Física. Ensaio: Pesquisa em Educação em Ciências, v. 14, p. 153-169, 2012.

VIANA. J.; RIBAS. F. C.; MALDANER, O. A especificidade no desenvolvimento de situação de estudo: perguntas do professor. In: ENCONTRO NACIONAL DE PESQUISA EM EDUCAÇÃO EM CIÊNCIAS, 8., Campinas. Anais...Campinas, 2011.

TORRES, J. R.; DELIZOICOV, D. Pesquisa em Educação Ambiental: articulações entre as propostas de Abordagem Temática e de Abordagem Relacional. In: ENCONTRO NACIONAL DE PESQUISA EM EDUCAÇÃO EM CIÊNCIAS, 6., Florianópolis. Anais...Florianópolis, 2007.

WATANABE-CARAMELLO, G.; STRIEDER, R.B.; GEHLEN, S.T. Desafios e Possibilidades para a Abordagem de Temas Ambientas em Aulas de Física. Revista Brasileira de Pesquisa em Educação em Ciências, v. 12, n.1, p. 205-222, 2012.

\section{SOBRE OS AUTORES}

KARINE RAQUIEL HALMENSCHLAGER. Licenciada em Física pela UNIJUÍ (2005), mestre (2010) e doutora (2014) em Educação Científica e Tecnológica pela UFSC. É professora do Departamento de Metodologia de Ensino (CED/UFSC) e tem interesse por temáticas relacionadas à Abordagem Temática, Formação Docente e Educação do Campo.

DEMÉTRIO DELIZOICOV. Licenciado em Física (USP, 1973); Mestre em Ensino de Ciências (USP, 1982) e Doutor em Didática (USP, 1991). Atua no Programa de PósGraduação em Educação Científica e Tecnológica da UFSC. Coordena o Grupo de Estudos e Pesquisa em Ensino de Ciências de Santa Catarina (GEPECISC).

Recebido: 28 de novembro de 2016.

Revisado: 31 de julho de 2017.

Aceito: 17 de agosto de 2017. 